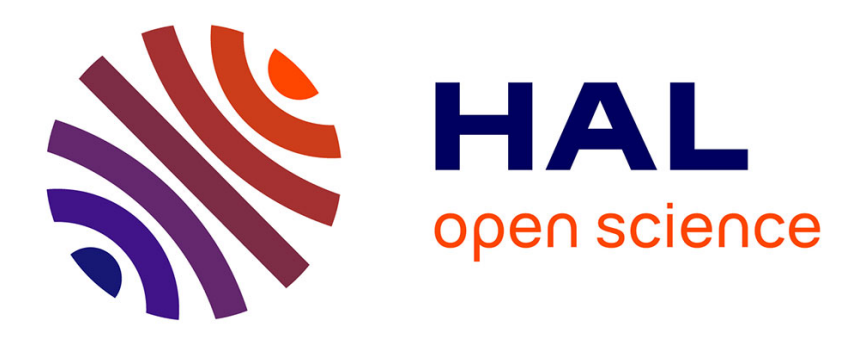

\title{
Analysis of reflected blast wave pressure profiles in a confined room
}

\author{
Isabelle Sochet, Pierre-Emmanuel Sauvan, Sophie Trelat
}

\section{To cite this version:}

Isabelle Sochet, Pierre-Emmanuel Sauvan, Sophie Trelat. Analysis of reflected blast wave pressure profiles in a confined room. Shock Waves, 2012, 22 (3), pp.253-264. 10.1007/s00193-012-0363-1. hal-00692601

\section{HAL Id: hal-00692601 \\ https://hal.science/hal-00692601}

Submitted on 3 May 2012

HAL is a multi-disciplinary open access archive for the deposit and dissemination of scientific research documents, whether they are published or not. The documents may come from teaching and research institutions in France or abroad, or from public or private research centers.
L'archive ouverte pluridisciplinaire HAL, est destinée au dépôt et à la diffusion de documents scientifiques de niveau recherche, publiés ou non, émanant des établissements d'enseignement et de recherche français ou étrangers, des laboratoires publics ou privés. 


\title{
ANALYSIS OF REFLECTED BLAST WAVE PRESSURE PROFILES IN A CONFINED ROOM
}

\author{
P.E. Sauvan ${ }^{1}$, I. Sochet ${ }^{1}$, S. Trélat ${ }^{2}$ \\ ${ }^{1}$ Ecole Nationale Supérieure d'Ingénieurs de Bourges - Institut PRISME - UPRES EA 4229 - 88 bvd \\ Lahitolle - 18020 Bourges cedex - France
}

Phone : 33-2-48-48-40-46 Fax 33-2-48-48-40-50

Email : isabelle.sochet@ensi-bourges.fr

${ }^{2}$ Industrial Risks, Fire, Explosion and Containment Assessment and Study Department / Fire and Explosion Studies and Assessment Section - Institute for Radiological Protection and Nuclear Safety (IRSN), France

\begin{abstract}
To understand the blast effects of confined explosions, it is necessary to study the characteristic parameters of the blast wave in terms of overpressure, impulse and arrival time. In a previous study, experiments were performed using two different scales of a pyrotechnic workshop. The main purpose of these experiments was to compare the TNT equivalent for solid and gaseous explosives in terms of mass to define a TNT equivalent in a reflection field and to validate the similitude between real and small scales. To study the interactions and propagations of the reflected shock waves, the present study was conducted by progressively building a confined volume around the charge. In this way, the influence of each wall and the origins of the reflected shock waves can be determined. The purpose of this paper is to report the blast wave interactions that resulted from the detonation of a stoichiometric propane-oxygen mixture in a confined room.
\end{abstract}

Keywords small scale experiments, TNT, plastrite, gaseous detonation, incident shock wave, reflected shock wave, confined explosion.

\section{Introduction}

To gain a better understanding of shock wave propagation in a confined environment, experiments were performed for a given configuration [1]. Real scale experiments, performed at DGA Techniques Terrestres (Bourges, France), and small scale experiments, performed at ENSIB (Bourges, France), were compared in terms of incident and reflected overpressures. Real scale experiments were performed with a solid explosive composed of plastrite in a pyrotechnic workshop. Small scale experiments $\left(1 / 10^{\text {th }}\right)$ were performed with a hemispherical gaseous charge composed of a propaneoxygen mixture (in stoichiometric proportions). The charge was located in a wooden structure that was representative of the pyrotechnic workshop. The purpose of this study was to compare scale experiments in a confined environment. The results showed good agreement between the two scales. 
Small scale experiments reduce costs and enable parametric studies to be conducted for the prevention and protection of accidental or intentional explosions.

In the present study, experiments regarding the origins of the reflected shock waves and the influence of each wall were performed.

\section{Experimental setup}

Small scale experiments were conducted at the PRISME Laboratory at ENSIB (Bourges, France). The test bench (Fig. 1) was a horizontal table on which the structure and the gaseous charge were placed. The gaseous mixture (stoichiometric propane - oxygen mixture) was blown through a soapy solution and the resulting half soap bubble represented the homogeneous hemispherical gaseous charge. The diameter of the charge was $66 \mathrm{~mm}$, which is equivalent to a TNT mass of $0.106 \mathrm{~g}$. The ignition device was composed of a high voltage device and two copper electrodes to which a $6 \mathrm{~mm}$ wire (nickelcopper) was welded. To ignite firing, the electrical ignition energy was released through the wire causing the gaseous charge to detonate. The nominal energy transmitted to the gaseous charge was 199,43 J. The transducers used were Kistler 603 B. Signals were sent to an oscilloscope and transferred to a computer for data processing. A full description of the experimental setup can be found in $[2,3]$.

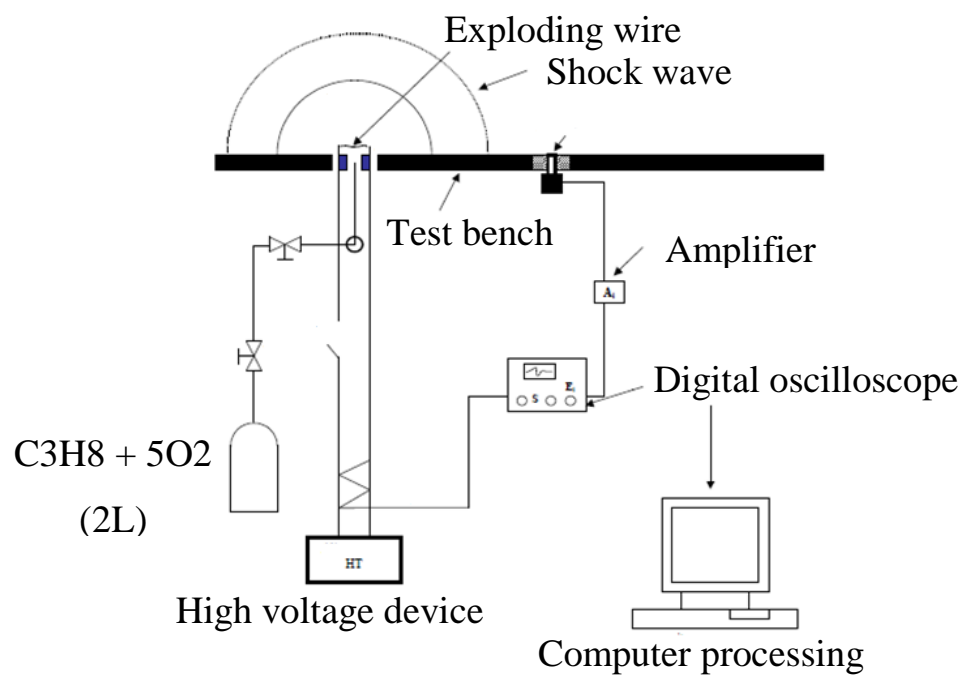

Fig. 1 Experimental setup

\section{Studied configuration}

The studied geometry was a semi-confined volume composed of four vertical walls; the dimensions of the structure were $400 \times 320 \times 250 \mathrm{~mm}$. The walls were made of medium-density, $16 \mathrm{~mm}$ thick fibreboard. The term "semi-confined volume" is used because the structure has no roof. Figs. 2 and 3 
present the geometry. The charge was located in the bottom right of the semi-confined volume and is represented by a circle (Fig. 2). Three sensors were located inside the semi-confined volume to record the time-varying pressure. These sensors are represented by circles labelled A, B, C in Fig. 2. Lastly, the walls are numbered from 1 to 4 to make the results easier to understand.

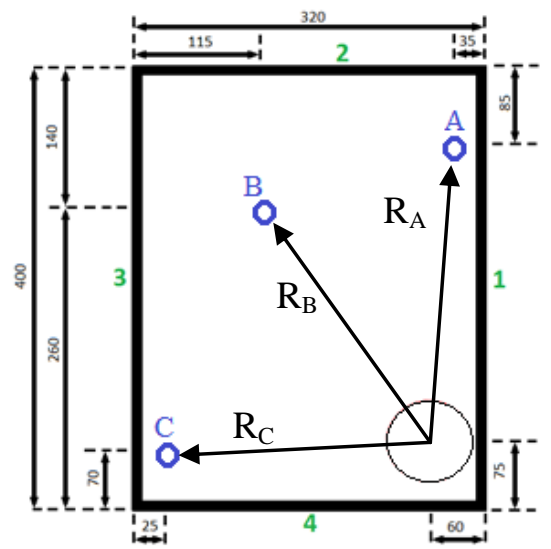

Fig. 2 Experimental configuration (distances in millimetres), $\mathrm{R}_{\mathrm{A}}=241, \mathrm{R}_{\mathrm{B}}=251, \mathrm{R}_{\mathrm{C}}=235$

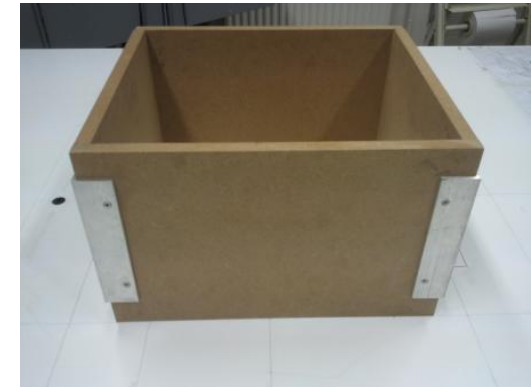

Fig. 3 Picture of the semi-confined volume

\subsection{Sensor A}

\subsubsection{Experiments with one wall}

To identify the reflected overpressure peaks, the first experiments were conducted with one wall. This facilitated a richer understanding of the results for the experiments with many walls. Figs. 4, 5, 6 and 7 show the pressure-time histories recorded by sensor A for the experiments with one wall.

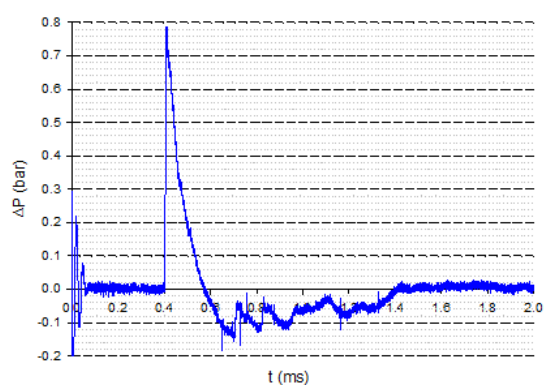

Fig. 4 Pressure-time history - Sensor A - Wall 1 alone

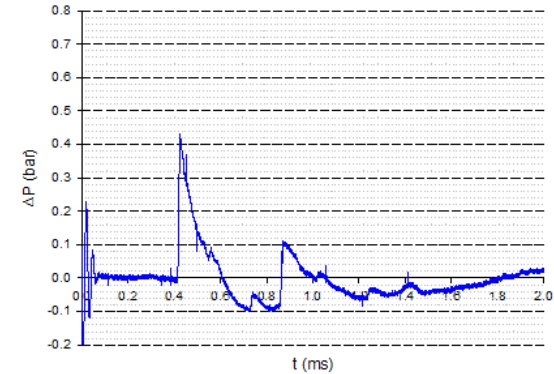

Fig. 5 Pressure-time history - Sensor A - Wall 2 alone 


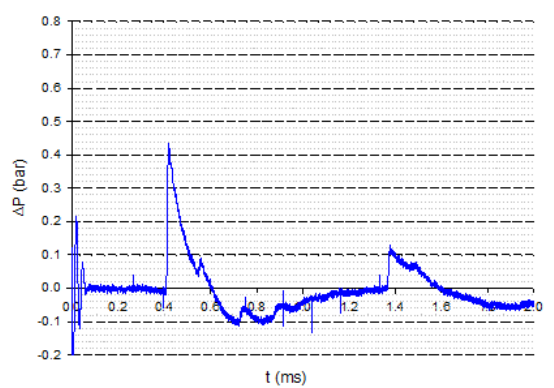

Fig. 6 Pressure-time history - Sensor A - Wall 3 alone

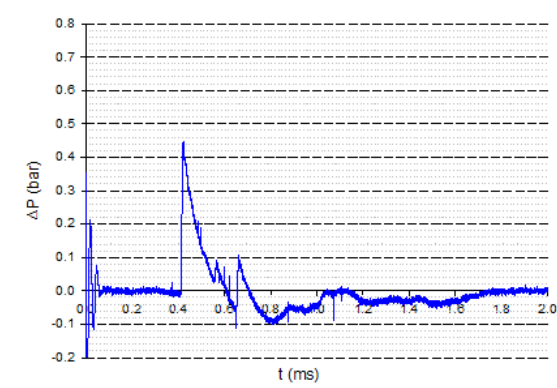

Fig. 7 Pressure-time history - Sensor A - Wall 4 alone

It can be seen that there was a large incident overpressure peak of 0.8 bar with Wall 1 , whereas the incident overpressures obtained with Walls 2, 3 and 4 were between 0.43 bar and 0.44 bar. The physical phenomenon taking place along Wall 1 was a Mach stem.

Sensor A, which was located $35 \mathrm{~mm}$ from Wall 1, was used to calculate the height of the Mach stem (Fig. 8).

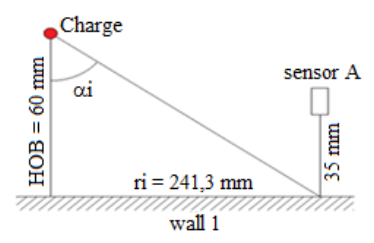

Fig. 8 Configuration for calculation of the Mach stem along Wall 1 - Top view - HOB = Height of burst

To calculate the height of the Mach stem, $h_{m}$, the incident shock wave Mach number, $M_{0}$, must be known. This Mach number is defined by the ratio of the incident shock wave celerity, $\mathrm{D}_{0}\left(\mathrm{~m} . \mathrm{s}^{-1}\right)$, to the sound velocity $\left(\mathrm{m}_{\mathrm{s}} \mathrm{s}^{-1}\right)$ (international standard atmosphere). The incident shock wave celerity was obtained by the ratio of the distance $\mathrm{R}_{\mathrm{A}}(\mathrm{mm})$ between the charge and the sensor to the arrival time, $\mathrm{t}_{\mathrm{a}}$ $(\mathrm{ms})$. The celerity expressed in $\mathrm{m} \cdot \mathrm{s}^{-1}$ is:

$$
D_{0}=\frac{R_{A}}{t_{a}}=\frac{241.3}{0.4}=603.2 \mathrm{~m} \cdot \mathrm{s}^{-1}
$$

Hence, the incident Mach number is equal to:

$$
M_{0}=\frac{D_{0}}{c}=\frac{603.2}{340}=1.77
$$

Angle $\beta_{\max }$ is the value of $\alpha_{\mathrm{i}}$ from which the shock wave propagates as a Mach stem.

$$
\beta_{\max }=\frac{1.75}{M_{0}-1}+39=41.3^{\circ}
$$


$\mathrm{r}_{\mathrm{i} 0}$ is the distance from which the shock wave propagates as a Mach stem.

$$
\begin{gathered}
r_{i 0}=H O B \times \tan \left(\beta_{\max }\right)=52.7 \mathrm{~mm} \\
h_{m}=H O B \times 0.07 \times\left[\frac{r_{i}}{r_{i 0}}-1\right]^{2}=53 \mathrm{~mm}
\end{gathered}
$$

When the Mach stem reached Sensor A, which was located $35 \mathrm{~mm}$ from Wall 1, its theoretical height was $53 \mathrm{~mm}$, and when it reached Wall 2, its theoretical height was $112 \mathrm{~mm}$ (a constant shock wave celerity is assumed).

It is important to note that the mean of the Mach stem peak at sensor A for all experiments that include wall 1 is 0.747 bar and the standard deviation is 0.033 bar. This result shows a good level of repeatability in explosive tests.

In Figs. 4, 5 and 6, a small overpressure peak located at $0.56 \mathrm{~ms}$ appeared immediately after the incident shock wave. This peak is visible in each figure; therefore, the corresponding shock wave cannot result from a wall reflection. Vanderstraeten et al. [5] highlighted that this peak appears during the detonation of a spherical (or hemispherical) gaseous charge. They demonstrated that in this case, the incident shock wave is immediately followed by a second shock wave whose amplitude is smaller. Actually, when the charge is ignited, an incident shock wave propagates in the surroundings while a rarefaction wave propagates from the contact surface (the surface between the surroundings and the initial gaseous mixture) towards the centre of the charge. When this rarefaction wave sufficiently decreases the burnt gas pressure with respect to the ambient pressure, a shock wave is created that propagates toward the centre of the explosive charge. When this secondary shock wave reaches the centre of the initial spherical gaseous charge, it is reflected (implosion) and then propagates in the same direction as the initial incident shock wave.

Throughout the present study, peaks that were present at $0.56 \mathrm{~ms}$ will be attributed to this phenomenon. Reflected shock waves consecutive to Walls 2, 3 and 4 reached sensor A at $0.86 \mathrm{~ms}, 1.4$ ms and $0.66 \mathrm{~ms}$, respectively.

As a result, it is now possible to identify the origins of the reflected overpressure peaks for experiments with many walls by investigating the chronology of the reflected overpressure peaks recorded by Sensor A.

\subsubsection{Experiments with two walls}

Figs. 9 to 14 present overpressures recorded by Sensor A for experiments with two walls 


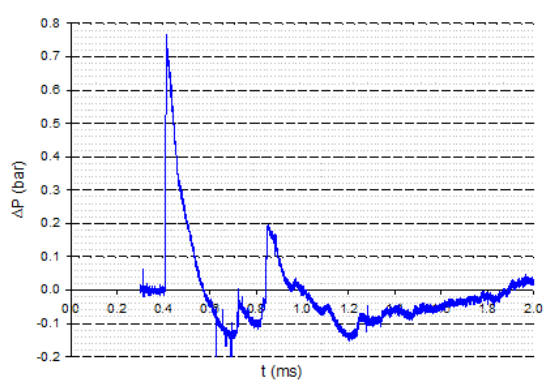

Fig. 9 Pressure-time history - Sensor A - Walls $1+2$

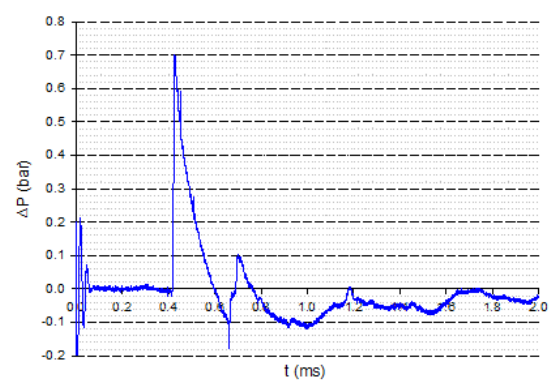

Fig. 11 Pressure-time history - Sensor A - Walls $1+4$

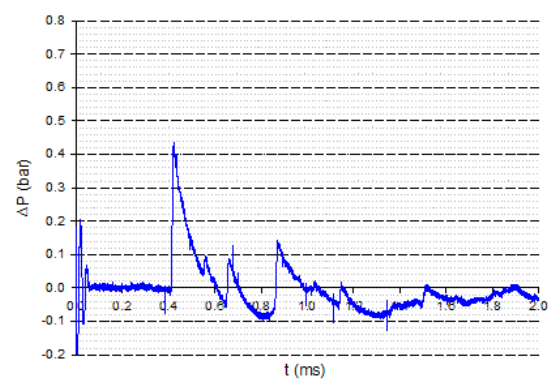

Fig. 13 Pressure-time history - Sensor A - Walls $2+4$

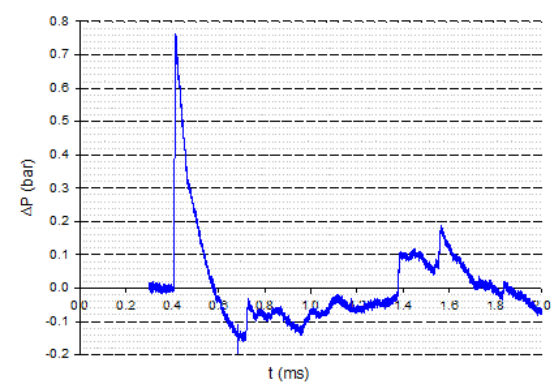

Fig. 10 Pressure-time history - Sensor A - Walls $1+3$

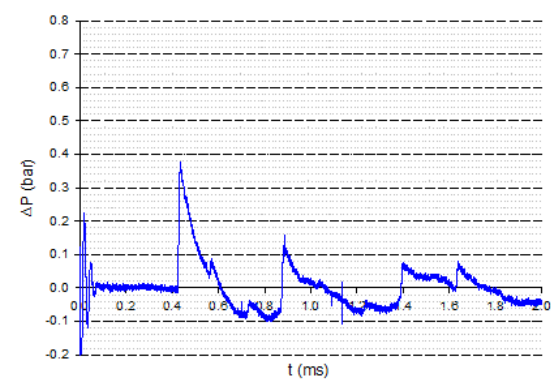

Fig. 12 Pressure-time history - Sensor A - Walls $2+3$

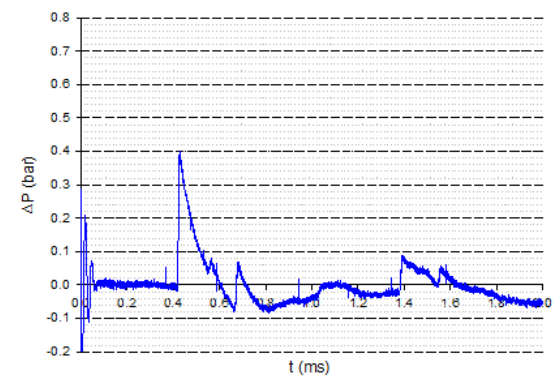

Fig. 14 Pressure-time history - Sensor A - Walls $3+4$

The reflected overpressure peaks reported on these figures can be easily identified owing to the results from the experiments with one wall. In Figs. 9, 10 and 11, the amplitude of the incident overpressure peak is the same as that observed with Wall 1 alone (see Fig. 4). This shows the propagation of a Mach stem along Wall 1. The reflected overpressure peaks resulting from the reflections for Walls 2, 3 and 4 appear in these figures at 0.84 $\mathrm{ms}, 1.38 \mathrm{~ms}$ and $0.66 \mathrm{~ms}$, respectively.

By identification with Fig. 5, it can be assumed that the first reflected overpressure peak located at $0.88 \mathrm{~ms}$ (Fig. 12) and the second reflected overpressure peak located at $0.86 \mathrm{~ms}$ (Fig. 13) correspond to a reflection on Wall 2. Based on the time-pressure profile obtained with Wall 4 alone (Fig. 7), the reflected overpressure peaks present at $0.66 \mathrm{~ms}$ and $0.68 \mathrm{~ms}$ for configurations 2 and 4 (Fig. 13), as well as 3 and 4 (Fig. 14), result from a reflection on Wall 4. In the same way, the second reflected overpressure peaks at $1.4 \mathrm{~ms}$ for configurations 2 and 3 (Fig. 12), as well as 3 and 4 (Fig. 14), were 
correlated with the time-pressure profile obtained with Wall 3 alone (Fig. 6); these peaks are therefore due to a reflection on Wall 3.

\subsubsection{Experiments with three walls}

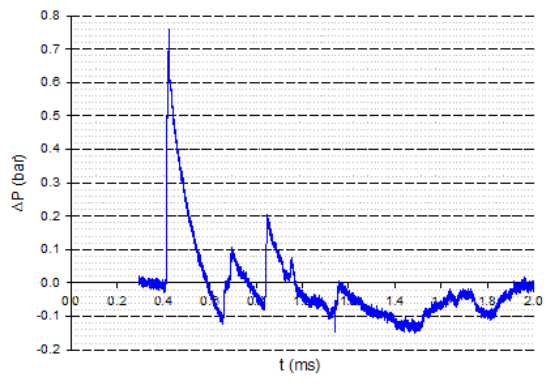

Fig. 15 Pressure-time history - Sensor A Walls $1+2+4$

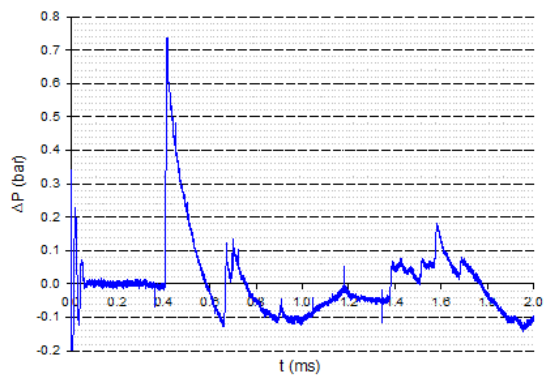

Fig. 17 Pressure-time history - Sensor A Walls $1+4+3$

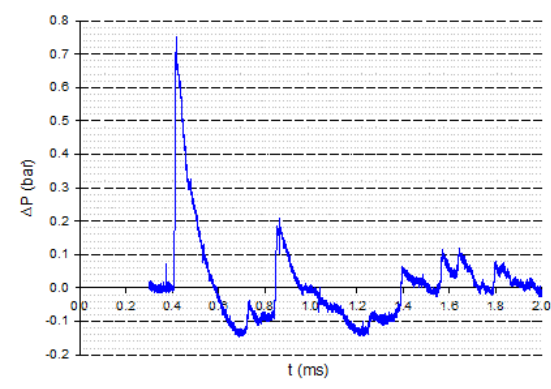

Fig. 16 Pressure-time history - Sensor A Walls $1+2+3$

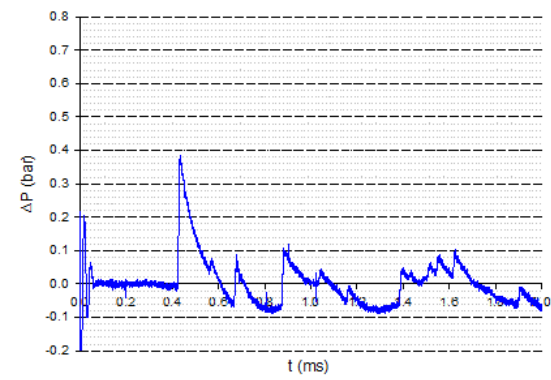

Fig. 18 Pressure-time history - Sensor A Walls $2+3+4$

The first incident overpressure peaks in Figs. 15, 16 and 17 show the Mach stem along wall 1 with a mean amplitude of 0.75 bar (0.38 bar without the Mach stem in Fig. 18).

Reflections on Wall 3 are identifiable in Figs. 16, 17 and 18 at 1.4 ms. However, many overpressure peaks appear after this peak. They result from the interactions of the first reflected shock wave on the other walls.

The overpressure peaks present at $0.84 \mathrm{~ms}$ in Figs. 15 and 16 correspond to reflections resulting from Wall 2. The amplitudes of these reflections were higher than those obtained in Fig. 18 at $0.88 \mathrm{~ms}$, which also resulted from Wall 2. When Wall 1 was present, a Mach stem appeared and the reflected overpressure was stronger than when Wall 1 was not present. This is why the arrival time is lower and why the amplitude is higher in Figs. 16 and 17 than in Fig. 18 for the reflected overpressure peak resulting from Wall 2.

In Figs 15, 17 and 18, the peaks located at $0.66 \mathrm{~ms}$ match with the reflected shock wave coming from Wall 4. This reflected shock wave was stronger in Figs. 15 and 17 (that is to say, when Wall 1 was 
present). Due to the proximity of Wall 4 to Wall 1, it is not possible that a Mach stem formed along Wall 1 before the incident shock wave reached Wall 4. However, because the charge was located in the corner formed by Walls 1 and 4, there was likely more confinement when Wall 1 was present.

The overpressure located at $1.16 \mathrm{~ms}$ in Fig. 15 can be assimilated to the reflection on Wall 2 of the reflected shock wave consecutive to Wall 4 . The reflected shock wave resulting from Wall 4 immediately followed the incident shock wave; a second shock wave may have been reflected by Wall 2 and may have followed the first reflected shock wave on this wall.

\subsubsection{Experiments with four walls}

Experiments with 1, 2 and 3 walls facilitated a richer understanding of the experiment with 4 walls. Fig. 19 represents the pressure-time history for an experiment with 4 walls.

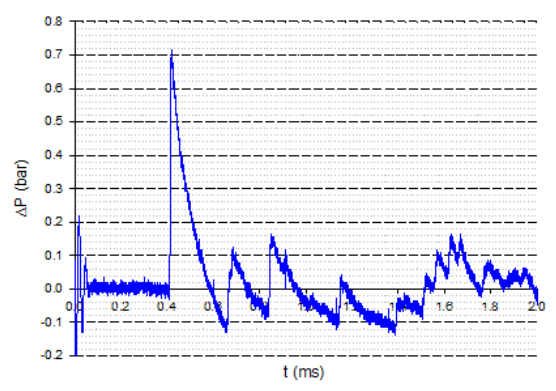

Fig. 19 Pressure-time history - Sensor A - Walls $1+2+3+4$

In Fig. 19, the reflected overpressure peaks coming from Walls 2 and 4 are located at $0.84 \mathrm{~ms}$ and 0.66 $\mathrm{ms}$, respectively. The incident overpressure peak shows the Mach stem propagation along Wall 1 with an amplitude of 0.72 bar. The overpressure peak located at $1.4 \mathrm{~ms}$ represents the reflected shock wave resulting from Wall 3. It can be observed (Fig. 19) that for experiments with four walls, this overpressure peak was lower $(0.05$ bar) than for experiments with fewer than 4 walls. The second reflected shock wave resulting from Wall 2 is located at $1.15 \mathrm{~ms}$. The reflected overpressure peaks located after $1.4 \mathrm{~ms}$ resulted from the many interactions of the first reflected shock waves on walls.

\subsection{Sensor B}

Results concerning Sensor B were analysed in the same way as the results for Sensor A. The overpressure peaks were located for each wall and then identified for experiments with several walls.

\subsubsection{Experiments with one wall}

Figs. 20 to 23 present the pressure-time histories recorded by Sensor B for experiments with one wall. 


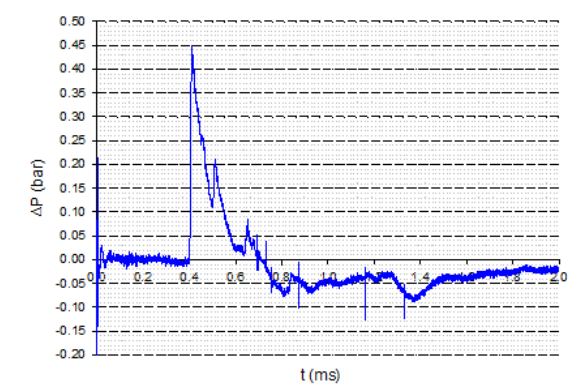

Fig. 20 Pressure-time history - Sensor B - Wall 1 alone

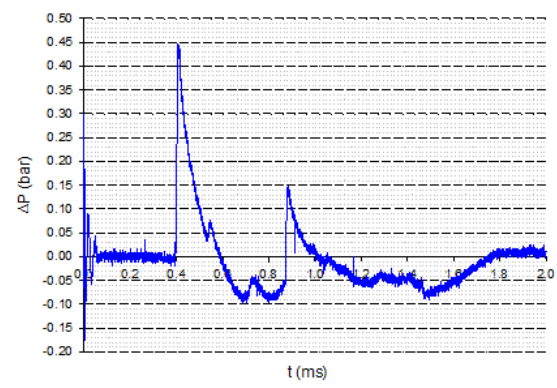

Fig. 22 Pressure-time history - Sensor B - Wall 3 alone

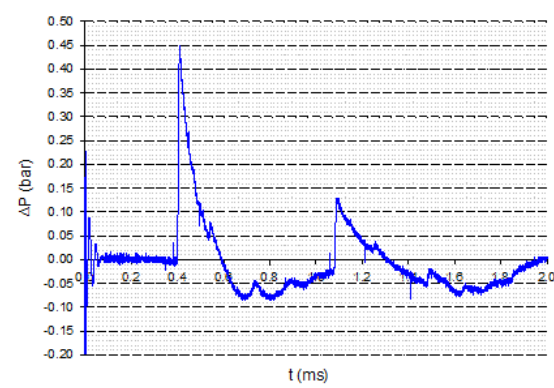

Fig.21 Pressure-time history - Sensor B - Wall 2 alone

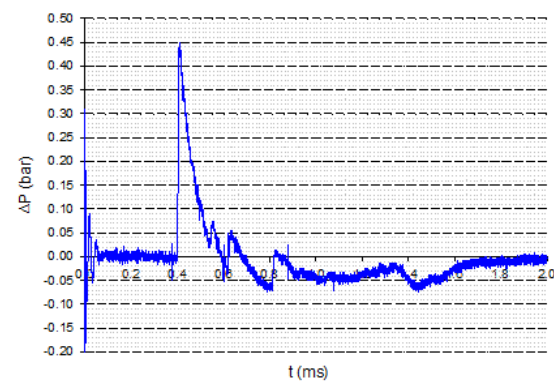

Fig.23 Pressure-time history - Sensor B - Wall 4 alone

In each figure, the incident overpressure peaks show the same physical characteristics in terms of arrival time $(0.4 \mathrm{~ms})$ and positive overpressure $(0.45 \mathrm{bar})$. The overpressure peaks corresponding to the second shock wave generated by the detonation of a gaseous spherical charge [5] happen at 0.56 $\mathrm{ms}$ and can be identified on each figure.

The reflected overpressure peaks located at $0.64 \mathrm{~ms}, 1.08 \mathrm{~ms}$ and $0.88 \mathrm{~ms}$ in Figs. 20, 21 and 22 match the reflected shock waves resulting from Walls 1, 2 and 3, respectively. In Fig. 23, the peak located at $0.62 \mathrm{~ms}$ corresponds to the reflected overpressure peak due to the reflection of the incident shock wave on Wall 4. However, a second overpressure peak located at $0.82 \mathrm{~ms}$ appears and can be assumed to be the result of the reflection on Wall 4 of the second shock wave from the detonation of a spherical gaseous charge [5].

\subsubsection{Experiments with two walls}

Figs. 24 to 29 present data from Sensor B for tests with two walls. 


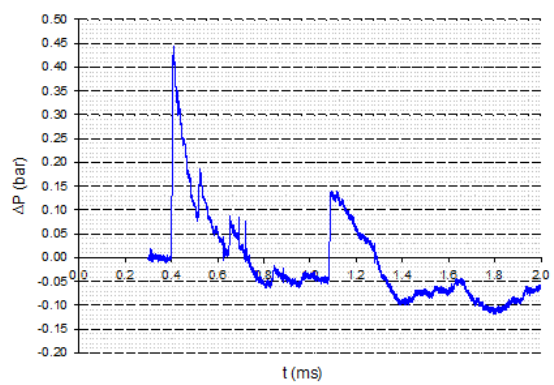

Fig. 24 Pressure-time history - Sensor B - Walls $1+2$

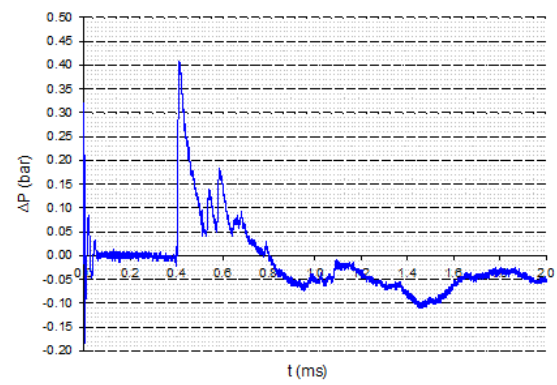

Fig. 26 Pressure-time history - Sensor B - Walls $1+4$

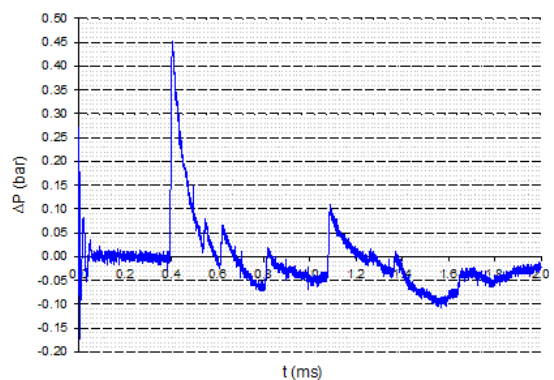

Fig. 28 Pressure-time history - Sensor B - Walls $2+4$

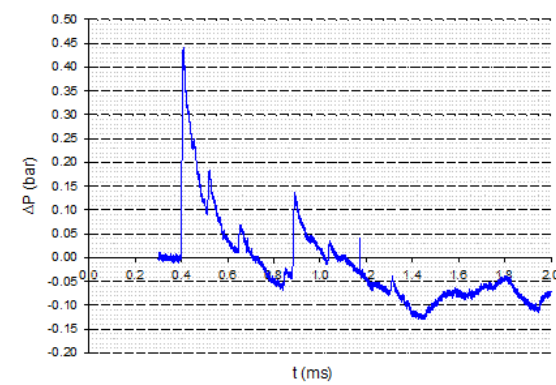

Fig. 25 Pressure-time history - Sensor B - Walls $1+3$

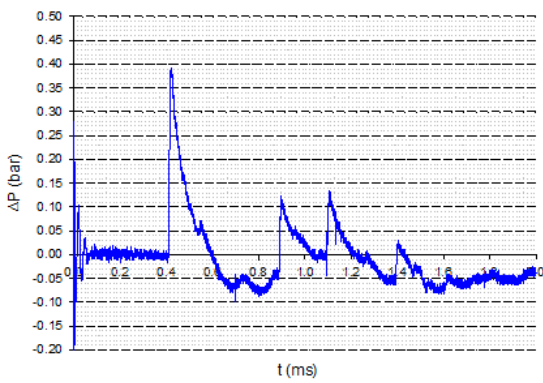

Fig. 27 Pressure-time history - Sensor B - Walls $2+3$

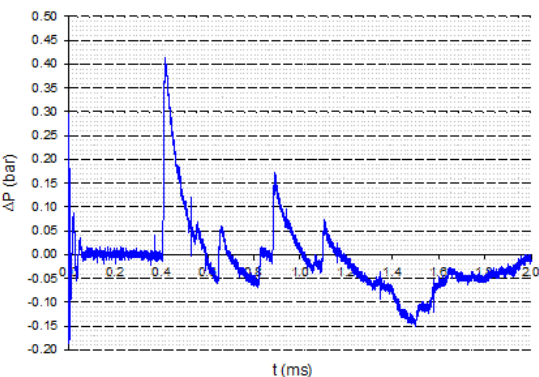

Fig. 29 Pressure-time history - Sensor B - Walls $3+4$

In Figs 24 and 25, the reflected shock waves resulting from Walls 2 and 3 can be identified at $1.08 \mathrm{~ms}$ and $0.88 \mathrm{~ms}$, respectively. In these figures, the peaks located at $0.64 \mathrm{~ms}$ represent the reflected shock waves resulting from Wall 1. In this report, the positive overpressure peak located between $0.54 \mathrm{~ms}$ and $0.56 \mathrm{~ms}$ will be assimilated to the second shock wave resulting from the detonation of a spherical gaseous charge [5].

In Fig. 26, the reflected overpressure peaks are hard to identify. The gaseous charge was located in the corner formed by Walls 1 and 4; therefore, the maximum reflected overpressure peak located at $0.6 \mathrm{~ms}$ may be an association of the two reflected shock waves resulting from Walls 1 and 4 . In fact, for tests with one wall, the arrival time of these reflected shock waves were $0.64 \mathrm{~ms}$ and $0.62 \mathrm{~ms}$, respectively. Interactions between these two shock waves can lead to a single shock wave with higher celerity and amplitude than the two initial shock waves. 
In Fig. 27, the reflected overpressure peaks located at $0.88 \mathrm{~ms}$ and $1.08 \mathrm{~ms}$ correspond to the reflections resulting from Walls 3 and 2, respectively. The reflected overpressure peak located at 1.4 ms may be a second reflection. In fact, the reflected shock wave resulting from Wall 3 was reflected on Wall 2. The reflected overpressure peaks located at 0.62 and $1.08 \mathrm{~ms}$ in Fig. 28 represent the reflections resulting from Walls 4 and 2, respectively. The peak located at $0.81 \mathrm{~ms}$ is the result of the reflection of the second incident shock wave [5] on Wall 4. This peak appears in Fig. 29 at $0.82 \mathrm{~ms}$ and before the reflected overpressure peak resulting from Wall 3, which is located at $0.88 \mathrm{~ms}$ and whose amplitude is higher than other tests with Wall 3. The peak located at $1.36 \mathrm{~ms}$ in Fig. 28 corresponds to the reflection on Wall 2 of the reflected shock wave resulting from Wall 4. In Fig. 29, the peak located at $0.64 \mathrm{~ms}$ corresponds to the reflection resulting from Wall 4 , and the peak located at $1.1 \mathrm{~ms}$ is the result of the reflection on Wall 3 of the reflected shock wave resulting from Wall 4.

\subsubsection{Experiments with three walls}

Figs. 30 to 33 represent pressure-time histories recorded by Sensor B for tests with 3 walls.

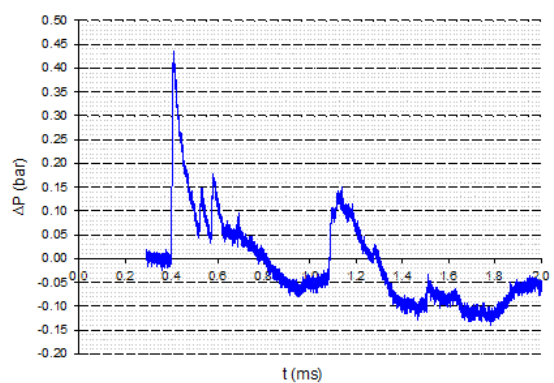

Fig. 30 Pressure-time history - Sensor B Walls $1+2+4$

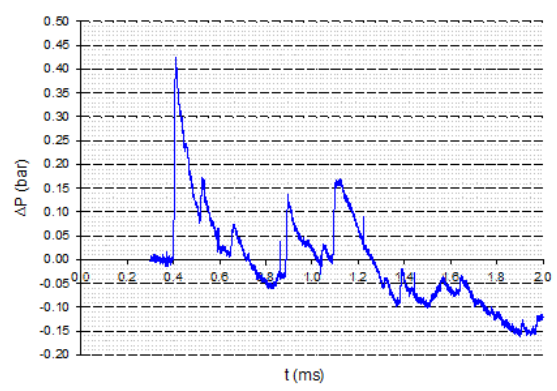

Fig. 32 Pressure-time history - Sensor B Walls $1+2+3$

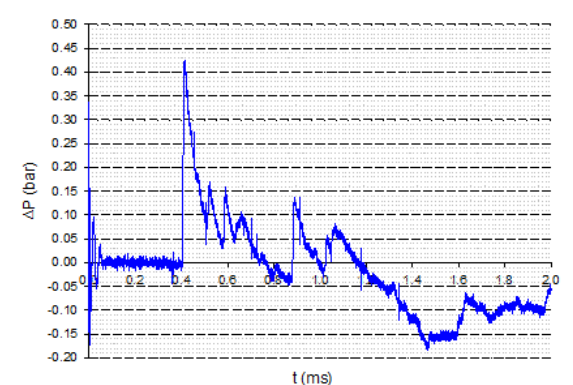

Fig. 31 Pressure-time history - Sensor B Walls $1+3+4$

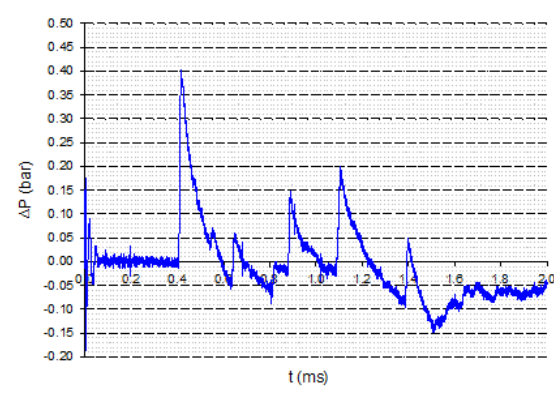

Fig. 33 Pressure-time history - Sensor B

Walls $2+3+4$

In Figs. 30 and 31, the interaction between the reflected shock waves resulting from Walls 1 and 4 are identified at $0.6 \mathrm{~ms}$, and the positive overpressure peaks located at $1.08 \mathrm{~ms}$ and $0.88 \mathrm{~ms}$ are 
assimilated to reflections resulting from Walls 2 and 3, respectively. The double peak located at 1.04 ms in Fig. 31 is the reflection on Wall 3 of the reflected shock waves resulting from Walls 1 and 4.

The peaks located at $0.62 \mathrm{~ms}, 0.88 \mathrm{~ms}$ and $1.08 \mathrm{~ms}$ in Fig. 32 correspond to the reflected shock waves resulting from Walls 1, 3 and 2, respectively. The reflected shock wave resulting from Wall 3 and being reflected on Wall 2 can be identified at $1.4 \mathrm{~ms}$.

The three first reflected overpressure peaks located at $0.64 \mathrm{~ms}, 0.88 \mathrm{~ms}$, and $1.08 \mathrm{~ms}$ in Fig. 33 correspond to the reflected shock waves resulting from Walls 4,3 and 2, respectively. The last overpressure peak located at $1.4 \mathrm{~ms}$ in this figure may be due to the addition of the reflected shock waves resulting from Walls 3 and 4 being reflected on Wall 2. In fact, it was seen previously that combining Walls 2 and 3 or Walls 2 and 4 resulted in an overpressure peak at 1.4 ms. However, in Fig. 33, the amplitude of the peak located at $1.4 \mathrm{~ms}$ is higher than the amplitude obtained for tests with only 2 walls. This peak may be due to the reflected shock waves resulting from Walls 3 and 4 being reflected on Wall 2.

\subsubsection{Experiments with four walls}

After an analysis of all configurations including tests with $1-3$ walls, it is now possible to more fully understand the test with four walls. Fig. 34 presents the pressure-time history recorded by Sensor B for an experiment with four walls.

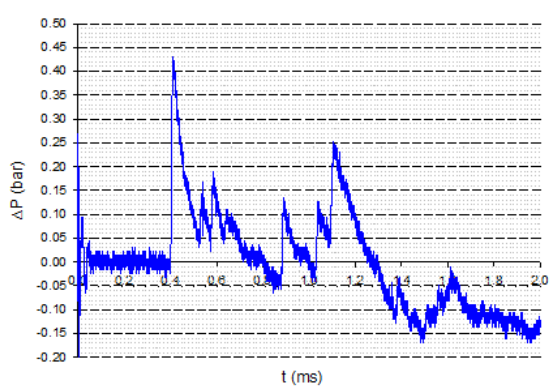

Fig. 34 Time-evolution of pressure - Sensor B - Walls $1+2+3+4$

The interaction of the reflected shock waves resulting from Walls 1 and 4 was identified at $0.6 \mathrm{~ms}$. The peak located at $0.88 \mathrm{~ms}$ is assumed to be due to the reflected shock wave from Wall 3. The overpressure peak located at $1.02 \mathrm{~ms}$ is the reflection on Wall 3 of the reflected shock waves resulting from Walls 1 and 4. The next overpressure peak, located at $1.08 \mathrm{~ms}$, is assimilated to the reflected shock wave resulting from Wall 2. After $1.24 \mathrm{~ms}$, the peaks result from multiple reflections and shock waves interactions. 


\subsection{Sensor C}

\subsubsection{Experiments with one wall}

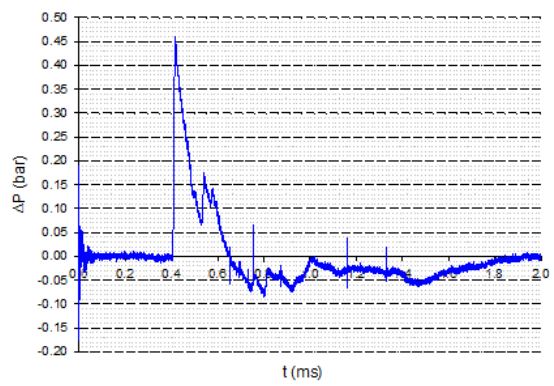

Fig. 35 Pressure-time history - Sensor C - Wall 1

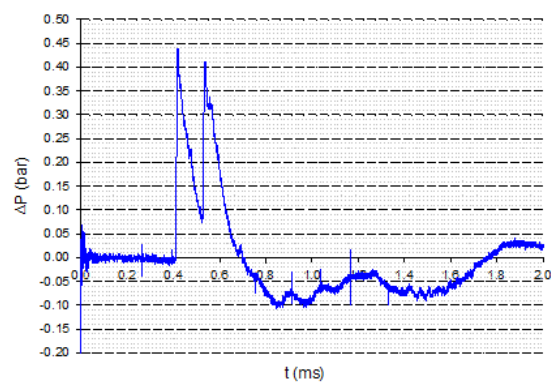

Fig. 327 Pressure-time history - Sensor C - Wall 3

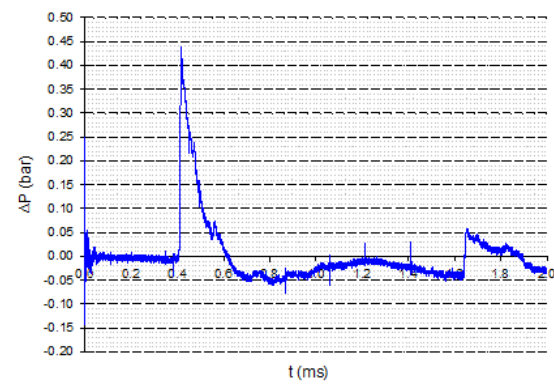

Fig. 36Pressure-time history - Sensor C - Wall 2

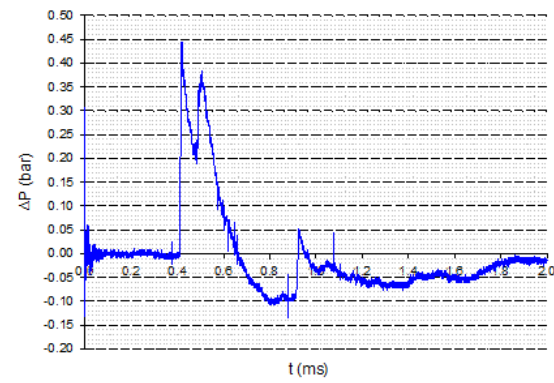

Fig. 38 Pressure-time history - Sensor C - Wall 4

In Fig. 36, the overpressure peak located at $1.64 \mathrm{~ms}$ corresponds to the reflected shock wave resulting from wall 2. In Figs. 35, 37 and 38, the overpressure peaks located at $0.56 \mathrm{~ms}$ correspond to the reflected shock waves resulting from walls 1, 3 and 4, respectively. Because Wall 1 is further from the sensor C $(295 \mathrm{~mm})$ than walls $3(25 \mathrm{~mm})$ and $4(70 \mathrm{~mm})$, the amplitude of the reflected shock wave resulting from this wall is lower, although the arrival times are similar.

However, it was seen previously that the shock wave resulting from a detonation of spherical gaseous charge is located between 0.54 and $0.56 \mathrm{~ms}$, reflected shock waves resulting from walls 1, 3 and 4 may be influenced by this phenomenon. In this case, the reflected overpressure can be overestimated.

\subsubsection{Experiments with two walls}




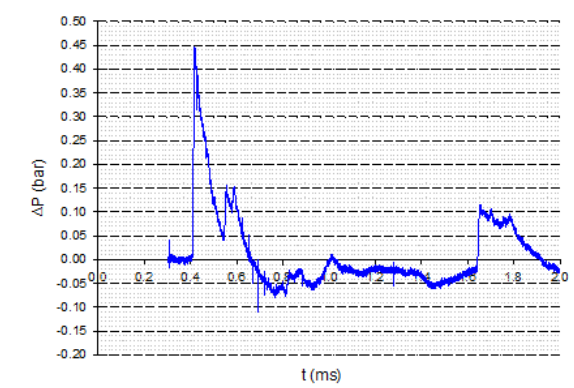

Fig. 39Pressure-time history - Sensor C - Walls $1+2$

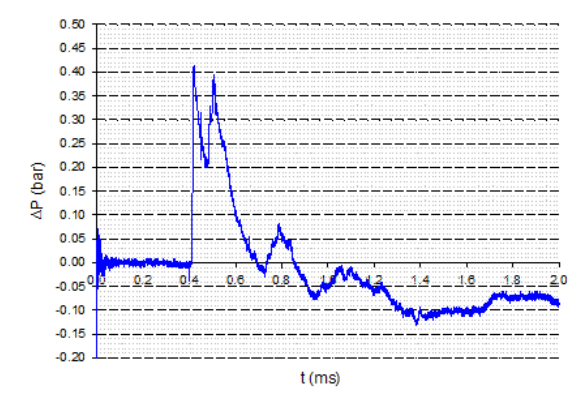

Fig. 41Pressure-time history - Sensor C - Walls $1+4$

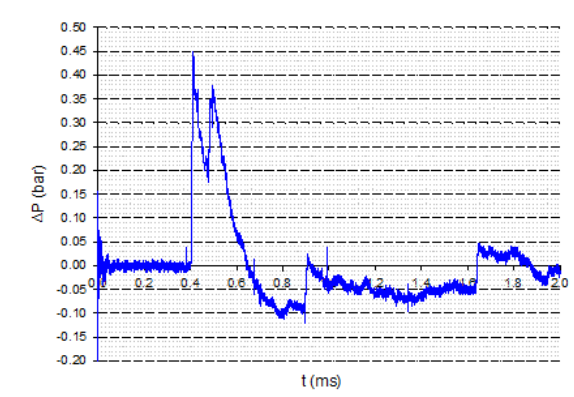

Fig. 43Pressure-time history - Sensor C - Walls $2+4$

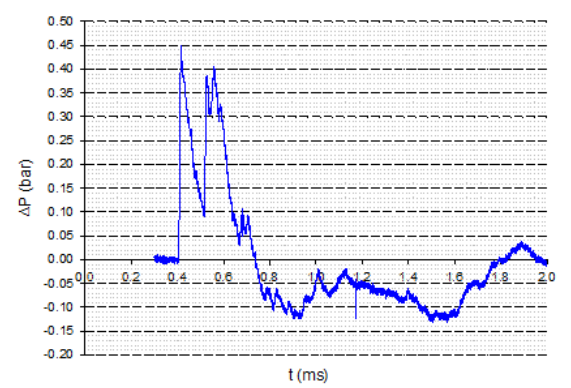

Fig. 40Pressure-time history - Sensor C - Walls $1+3$

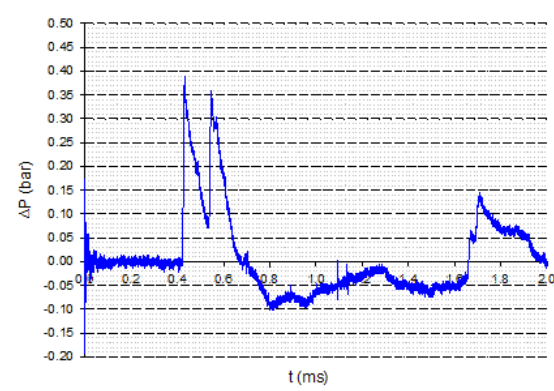

Fig. 42Pressure-time history - Sensor C - Walls $2+3$

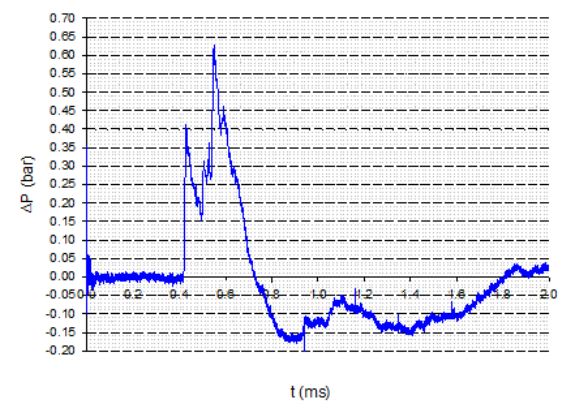

Fig. 44Pressure-time history - Sensor C - Walls $3+4$

In Figs. 40, 41 and 44, which represent all combinations with Walls 1, 3 and 4, the reflected overpressure peaks located just behind the incident overpressure peak result from a summation and interaction of the reflected shock waves resulting from these 3 walls. The most relevant result is shown in Fig. 44 where the reflected overpressure is 1.5 times higher than the incident overpressure. Sensor C was located in the corner formed by Walls 3 and 4; therefore, the confinement created by these 2 walls may explain this result.

In Figs. 39, 42 and 43, the first reflected overpressure peaks correspond to the reflected shock waves resulting from Walls 1,3 and 4, respectively, whereas the overpressure peaks located at $1.64 \mathrm{~ms}$ result from Wall 2. The reflected overpressure peak located at $0.8 \mathrm{~ms}$ in Fig. 41 results from a double reflection. In fact, because the hemispherical gaseous charge was located in a corner close to Walls 1 and 4 , the reflected shock wave coming from Wall 1 was reflected again on Wall 4 and vice versa. 
A double peak appears in Fig. 42 at 1.66 ms. It was seen previously that the first peak corresponded to the reflected shock wave coming from Wall 2 and the second peak corresponded to the reflection of this first reflected shock wave on Wall 3.

\subsubsection{Experiments with three walls}

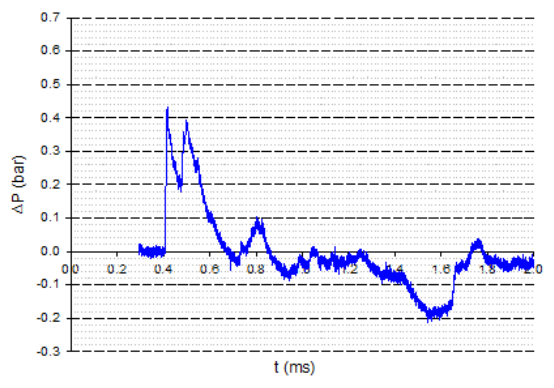

Fig. 45Time-evolution of pressure - Sensor C Walls $1+2+4$

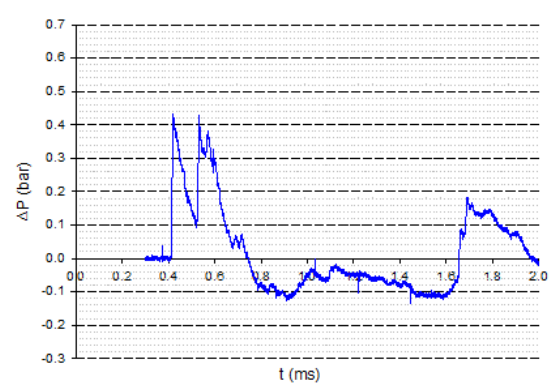

Fig. 47 Time-evolution of pressure - Sensor C Walls $1+2+3$

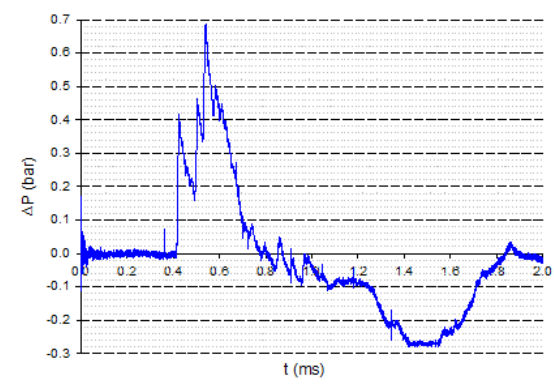

Fig. 46Time-evolution of pressure - Sensor C Walls $1+3+4$

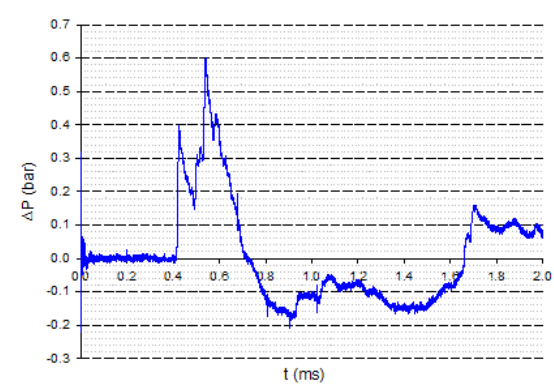

Fig. 48 Time-evolution of pressure - Sensor C Walls $2+3+4$

It can be seen in Figs. 46 and 48 that the reflected overpressure peak located immediately behind the incident overpressure peak is important when Walls 3 and 4 are present. The effect is more important when Wall 1 is added (fig. 46). In fact, the reflected shock waves resulting from Walls 1,3 and 4 reached Sensor A at the same time. This effect involves the addition of these three shock waves and the result is the creation of an important reflected overpressure peak.

The reflected shock wave resulting from Wall 2 is identifiable in Figs. 47 and 48 at 1.64 ms. In Figs. 47 and 48, the double reflected overpressure peak appears with the presence of Walls 2 and 3. For configurations with Walls 1+3+4 (Fig. 46) and 2+3+4 (Fig. 48), the reflected overpressure peaks are higher than the incident overpressure peak. This shows that when Walls 3 and 4 are present, the reflected shock waves are stronger than the incident shock wave. It is important to notice that negative overpressures were stronger for experiments with three walls than for experiments with two walls. In fact, the maximal negative overpressure was -0.27 bar; this value was reached with Walls $1+3+4$. 


\subsubsection{Experiments with four walls}

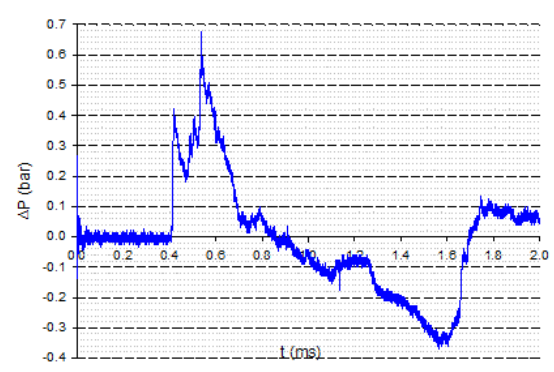

Fig. 49Time-evolution of pressure - Sensor C - Walls $1+2+3+4$

In Fig. 49, all the overpressure peaks presented previously are identifiable. The strong reflected overpressure peak between $0.48 \mathrm{~ms}$ and $0.68 \mathrm{~ms}$ reflects the addition of the reflected shock waves resulting from Walls 1,3 and 4 . The reflected overpressure peak located at $0.8 \mathrm{~ms}$ is the result of the reflection on Wall 4 of the reflected shock wave resulting from Wall 1, or vice versa. The rise of the pressure after $1.6 \mathrm{~ms}$ was caused by the reflected shock wave resulting from Wall 2. This rise was stronger than the negative overpressure ( -0.35 bar). In fact, for previous tests (1,2 and 3 walls), the overpressure peak amplitude of the shock wave resulting from Wall 2 was approximately 0.1 bar, whereas in the case with 4 walls, the amplitude was approximately 0.45 bar.

\section{Conclusion}

Wall by wall experiments facilitated the identification of reflected overpressure peaks and the experiments confirmed the propagation of a Mach stem along Wall 1. This phenomenon is more commonly encountered when the detonation takes place at altitude. However, this simple analysis allowed us to identify the three or four first reflected overpressure peaks that represent the first reflections of the incident shock wave.

During the detonation of an explosive charge in a semi-confined environment, damages caused by the negative phase of the shock waves can be more significant than the ones caused by the positive phase.

These results are unusual for studies of shock waves consecutive to detonation, especially in terms of impulses. In fact, these results are generally expected for deflagration regimes in which positive and negative impulses are in the same order of magnitude.

Acknowledgment This work has been performed thanks to Délégation Générale de l'Armement Technique terrestre, IRSN, MBDA France, Nexter Munitions, CG18 and Agglo Bourges for scientific discussions and financial support. 


\section{References}

1. Sauvan P.E. : Etude d'essais d'explosions en atelier pyrotechnique et simulation à petite échelle, Report DGA TT / PNRI nº8 02 028, 2009. Bourges, France

2. Trélat S., Sochet I., Autrusson B., Cheval K., Loiseau O.: Strong explosion near a parallelepipedc structure. Journal Shock Waves V.16, 4-5, 349-357 (2007)

3. Trélat S., Sochet I., Autrusson B., Cheval K., Loiseau O.: Impact of a shock wave on a structure on explosion at altitude, Journal of Loss Prevention in the Process Industries V.20, 509-516 (2007)

4. Kinney G.F., Graham K.J.: Explosives Shocks in Air, Second Edition, Springer-Verlag, New-York (1985)

5. Vanderstraeten B., Lefebvre M., Berghmans J.: A simple blast wave model for bursting spheres based on numerical simulation, Journal of Hazardous Materials vol. 46, 145-147 (1996) 